Document downloaded from:

http://hdl.handle.net/10251/108206

This paper must be cited as:

Escribano-Quintana, JA.; García-Fayos, J.; Serra Alfaro, JM. (2017). Shaping of 3YSZ porous substrates for oxygen separation membranes. Journal of the European Ceramic Society. 37(16):5223-5231. doi:10.1016/j.jeurceramsoc.2017.05.032

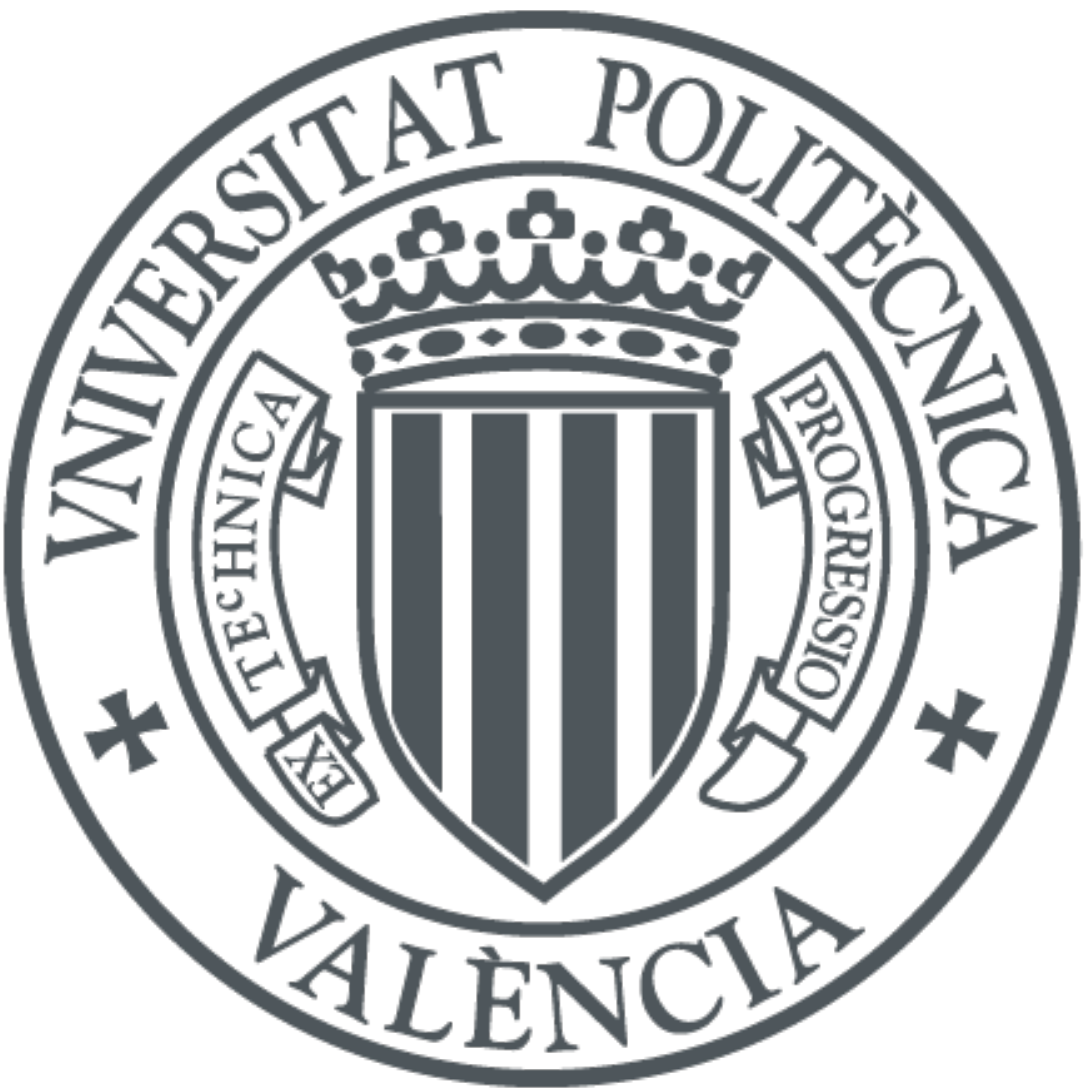

The final publication is available at

https://doi.org/10.1016/j.jeurceramsoc.2017.05.032

Copyright Elsevier

Additional Information 


\title{
Shaping of 3YSZ Porous Substrates for Oxygen Separation Membranes
}

Juan A. Escribano, Julio García-Fayos, José M. Serra*

${ }^{1}$ Instituto de Tecnología Química (UPV-CSIC), Universitat Politècnica de València, Consejo Superior de Investigaciones Científicas, Avenida de los Naranjos s/n, 46022 Valencia, Spain “jmserra@itq.upv.es

\begin{abstract}
In recent years, asymmetric membranes based on mixed ionic-electronic conductors (MIEC) have gained importance in practical gas separations. MIEC ceramic materials show high-energy efficiency and high-temperature resistance, which allows direct integration in industrial processes. Thin layers are supported on porous substrates that provide mechanical strength. In the asymmetric membrane manufacture, the control of support porosity and microstructure is crucial. Colloidal processing is an interesting method that allows controlling the final microstructure in both surfaces and bulk, with high reproducibility. Here, the development of asymmetric membranes with a top functional layer made of $\mathrm{Ce}_{0.8} \mathrm{Gd}_{0.2} \mathrm{O}_{1.9} / \mathrm{Ni}_{2} \mathrm{FeO}_{4}$ composite is presented and aims to maximize oxygen permeation and membrane robustness. The porous substrate is prepared by slip casting while the functional layers by screen-printing. The effect of pore former volume and particle morphology were studied. The combination of spherical and flake-like PMMA particles enabled to generate open porosity suitable for fast gas transport.
\end{abstract}




\section{Introduction}

Oxygen production has high impact in several industries due to both its use as a reagent in chemical processes and its use to provide a more efficient combustion in thermal processes. Therefore, there is a need to efficiently produce high-purity oxygen at different scales. The main way to obtain oxygen is by cryogenic distillation of air [1]. However, this process presents important drawbacks related to the high energy requirements and large plant size. One of the alternatives is the use of gas-separation ceramics membranes, which allows the selective permeation of the oxygen by diffusion through the ceramic oxide lattice. Among other advantages, ceramic membranes allow the in situ $\mathrm{O}_{2}$ production at small-to-medium scale where other technologies such as the cryogenic are not economically feasible. This kind of membranes should present both ionic and electronic conductivity [2,3], since oxygen permeates thanks to the presence of oxygen vacancies in the crystalline lattice driven by the oxygen pressure gradient across the membrane, and a counter-diffusion of electrons occurs to balance the charge at both sides of the membrane. In contrast to the difficulty to find a single materials with high thermo-chemical stability and proper mixed ionic-electronic conduction, dual-phase composite materials have enabled reaching promising results [4]. In this paper, a combination of a spinel $\mathrm{Ni}_{2} \mathrm{FeO}_{4}$ (NFO) and a fluorite $\mathrm{Ce}_{0.8} \mathrm{Gd}_{0.2} \mathrm{O}_{2-\delta}$ (CGO) is used, obtaining a stable composite material able to permeate oxygen $[5,6]$. NFO spinel could present both $\mathrm{n}$ type and p-type electronic conductivity depending on the different synthesis techniques and crystal sizes. The $\mathrm{n}$-type behavior has been attributed to the presence of $\mathrm{Fe}^{2+}$, which enables the electron hopping from $\mathrm{Fe}^{2+}$ to $\mathrm{Fe}^{3+}$. The $\mathrm{p}$-type behavior has been related to the presence of $\mathrm{Ni}^{3+}$ and hole hopping from $\mathrm{Ni}^{3+}$ to $\mathrm{Ni}^{2+}$. The last can be assigned to the deficiency or excess in $\mathrm{Ni}$, because a $\mathrm{Ni}$ excess corresponds to $\mathrm{Fe}^{3+}$ deficiency compensated with $\mathrm{Ni}^{3+}$ (p-type) while a Ni deficiency corresponds to a $\mathrm{Fe}^{2+}$ compensation (n-type)[7]. On the other hand, the CGO present high ionic conductivity and stability $[8,9]$ and together with NFO generates a composite material with high $\mathrm{O}_{2}$ permeation features but due to the presence of two phases, the influence of the grain boundary is relevant.

When the oxygen flux is determined by the transport through the membrane bulk, the flux at the steady state through membrane can be describe by the Wagner equation:

$$
j_{O_{2}}=\frac{R T}{16 F^{2}} \sigma_{a m b} \frac{1}{L} \ln \frac{p_{O_{2}}^{\prime}}{p_{O_{2}}^{\prime \prime}}
$$

where $R$ is the gas constant $(\mathrm{J} / \mathrm{Kmol}), T$ is the temperature $(\mathrm{K}), \mathrm{F}$ is the Faraday constant $(\mathrm{C} / \mathrm{mol}), \sigma_{\mathrm{amb}}$ is the ambipolar conductivity, $\mathrm{L}$ is the membrane thickness $(\mathrm{m})$ and $\mathrm{p}_{02}^{\prime}$ and $\mathrm{p}^{\prime \prime}{ }_{02}$ are the oxygen partial pressure at both membrane sides. Note that, for a sufficiently thin membrane, the permeation can be limited by other phenomena such as oxygen surface gassolid exchange, gas transport in the porous substrate and gas transport in the open gas chambers.

According to the Wagner equation (1), a membrane should be as thin as possible in order to optimize the permeation flux. In this sense, asymmetric membranes allow reaching thin layers of the separation membrane with high mechanical properties without decreasing their flux properties [10,11]. These membranes are constituted by a dense layer of MIEC material/composite deposited on a porous substrate [12]. There is a wide range of techniques that allows preparing thin layers on different substrates [13-15]. The choice of the technique must be in accordance with the characteristics of both the layer and the substrate. For asymmetric membranes, suspension-spraying and screen-printing processes allow the 
deposition of the membrane layer with controller thickness with high reproducibility and superficial quality on plane substrate of different areas.

The requirements of the porous support respect to the MIEC layer are that they should present chemical compatibility, similar thermal expansion coefficient, good gas permeation and excellent mechanical properties under operation conditions [16]. In this sense, 3 mol\% Yttria stabilized Zirconium (3YSZ) meets the requirements as substrate, due to it high chemical stability and high mechanical properties. As for the layer deposition, there are numerous processing routes to obtain porous 3 YSZ substrate. In the recent years, substrate processing of asymmetric membranes has been focused in tape casting $[17,18]$, freeze casting $[19,20]$, pressing $[21,22]$ and extrusion processing $[23,24]$, while slip casting has been received less attention $[25,26]$. In previous works on membrane manufacture by slip casting, the porosity in the substrate was induced by careful control of (i) the particle size during processing and (ii) the thermal treatment. However, the use of pore-former particles enables to tailor the porosity and sinter the substrate at higher temperatures without much porosity loss, what in turn increases the membrane mechanical properties. On the other hand, slip casting is one of the most common industrial methods for ceramic processing that provides high dispersion degree of ceramic phases and accurate control of the microstructure in cast porous materials $[27,28]$. Slip casting is a simple, industrially and economically viable shaping technique and allows obtaining complex geometries/morphologies than other processing techniques. In addition, the colloidal processing implies the formation of suspensions in aqueous media, which is a drawback in the case of both non-oxide ceramic and metal particles, due to the elevated reactivity of these materials with the suspension media. From an electrochemical point of view, water is one of the more complex liquid media to work with. It has a very high polar moment, which requires careful control of the conditions of the suspensions $[29,30]$.

The present work focuses on the development of asymmetric membranes by different processing methods with a top functional layer made of the $\mathrm{Ce}_{0.8} \mathrm{Gd}_{0.2} \mathrm{O}_{1.9} / \mathrm{Ni}_{2} \mathrm{FeO}_{4} /$ (CGO-NFO) dual-phase material with the aim to maximize oxygen permeation and membrane robustness under harsh operation conditions, i.e. high temperature, important pressure gradient across the membrane and high $\mathrm{CO}_{2}$ concentrations. In this case, the porous substrate of the membrane is prepared by slip casting while the functional layer by screen-printing.

\section{Materials and methodology}

The membrane substrates were prepared using a commercial 3YSZ powder (TZ-3YS-E, TOSOH Corporation, Japan) with $90 \mathrm{~nm}$ of average particle size, a specific surface area of $7.30 \mathrm{~m}^{2} / \mathrm{g}$ and $6.05 \mathrm{~g} / \mathrm{cm}^{3}$ of density. A micrograph of the as received powders is present in Figure 1. As can be observed, the 3 YSZ powder is formed by agglomerates of nanometric particles. 


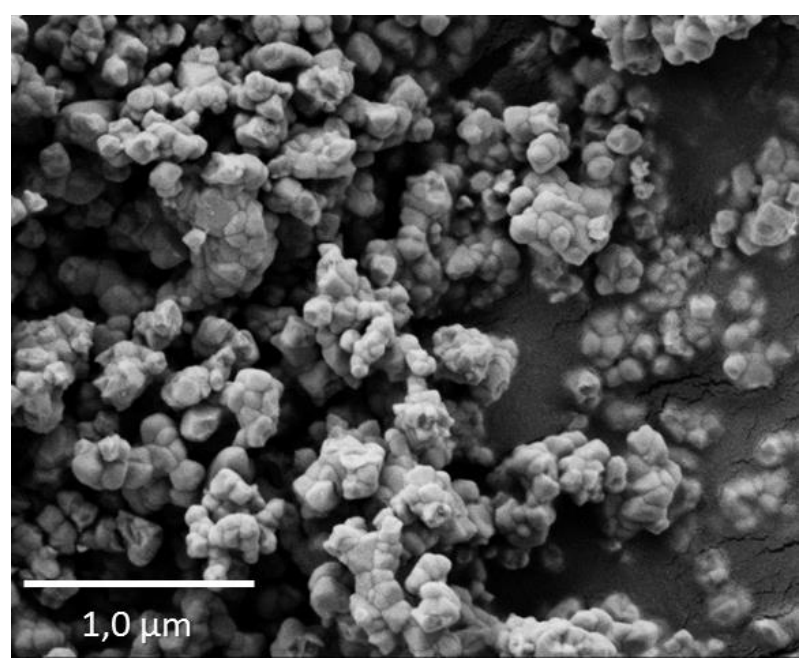

Figure 1 Micrograph of the 3YSZ powder as received

The characterization of the colloidal properties of the 3YSZ comprised the zeta potential measurement as a function of $\mathrm{pH}$ and was performed using a suspension with a solid content of $0.1 \mathrm{~g} / \mathrm{L}$ in $10^{-2} \mathrm{M} \mathrm{KCl}$, using $\mathrm{HTMA}$ and $\mathrm{HNO}_{3}$ to adjust the $\mathrm{pH}$. Measurements were carry out using a Zetasizer Nano ZS (Malvern, UK).

In order to introduce porosity in the microstructure of the final body, different polymethylmethacrylate (PMMA) powders were added to the 3YSZ slurries. Table 1 presents the characteristics of the pore formers used in the slurries, and Figure 2 shows the corresponding SEM micrographs.

Table 1 Morphological characteristics of the PMMA particles

\begin{tabular}{|c|c|c|c|}
\hline Code & Size dv50 $(\mu \mathrm{m})$ & Morphology & Reference \\
\hline S-006 & 6.0 & Spherical & MX-500, Esprix (USA) \\
\hline S-020 & 20 & Spherical & MX-2000, Esprix (USA) \\
\hline S-050 & 50 & Spherical & $\begin{array}{c}\text { Altuglass BS100, Arkema } \\
\text { (France) }\end{array}$ \\
\hline F-150 & 150 & Flakes & $\begin{array}{c}\text { Porlat K85, Zschimmer \& } \\
\text { Schwarz (Germany) }\end{array}$ \\
\hline
\end{tabular}



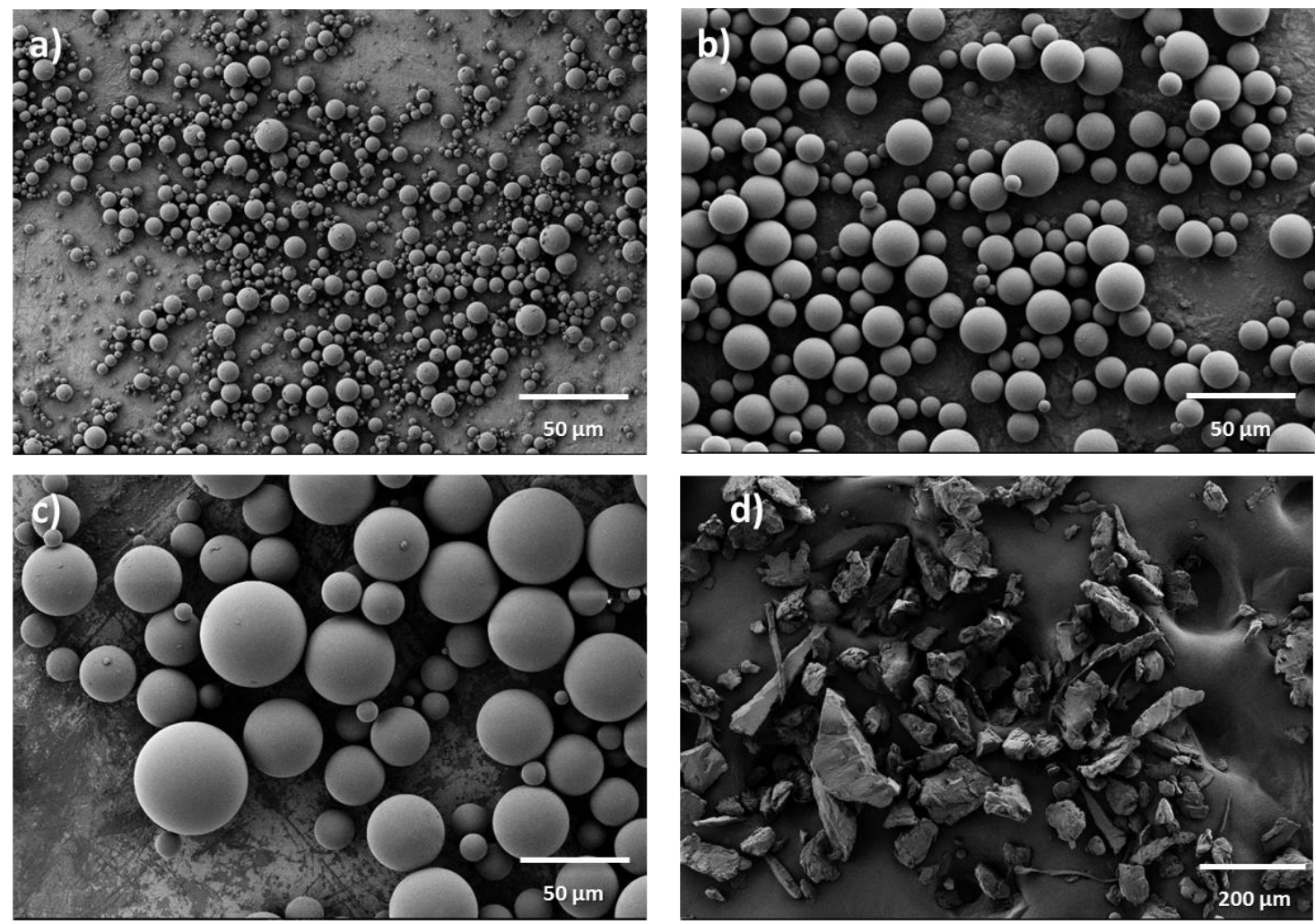

Figure 2 Micrographs of the pore former used a)S-006, b) S-020, c) S-050 and d) F-150

To measure the rheology, a Haake Mars rheometer (Thermo Scientific, Germany) with a double-cone plate fix of $60 \mathrm{~mm}$ of diameter and angle of $2 \circ$ (DC60/2) was used. Tests were performed in a control rate mode (CR) shearing from 0 to $1000 \mathrm{~s}^{-1}$ in 2 minutes, dwelling at $1000 \mathrm{~s}^{-1}$ for 1 minute and shearing down to $0 \mathrm{~s}^{-1}$ in 2 minutes and control stress from 0 to $6 \mathrm{~Pa}$ in 2 minutes and down to $0 \mathrm{~Pa}$ in the same time. All tests were done at a constant temperature of $23 \pm 0.5 \circ C$. The applied high-shear rates during up-ramps are enough to achieve a reproducible suspension microstructure, dependent only on the suspension composition, but not on the slurry preparation history [31]. The flow curves were fitted using the Cross model (eq. 2), which describes the pseudoplastic behavior.

$$
\eta=\eta_{\infty} \frac{\eta_{0}-\eta_{\infty}}{1+(C Y)^{n}}
$$

where $\eta_{0}$ and $\eta_{\infty}$ are the extrapolation of the viscosity to zero and infinity respectively, $C$ is a time constant and $\mathrm{n}$ is the rate constant, and it is a parameter which is related with the dependence of viscosity on the shear rate. The Cross model describes the limit behavior of the standing suspension and at infinite shear rate, therefore not only gives information about suspension viscosity but about its stability.

For the MIEC membrane layers, a combination of $\mathrm{Ce}_{0.8} \mathrm{Gd}_{0.2} \mathrm{O}_{1.9}$ and $\mathrm{Ni}_{2} \mathrm{FeO}_{4}$ (CGO-NFO) was prepared by solid state reaction method, comprising the sintering of the ball-milled single oxides at $1250 \stackrel{\circ}{ } \mathrm{C}$ followed by further ball milling. The particle size of the powder is between $0.9 \mu \mathrm{m}$ to $10.1 \mu \mathrm{m}$, with a dv $\mathrm{dv}_{50}$ of $3.0 \mu \mathrm{m}$. The MIEC layer was deposited onto the substrates by screen-printing, using a dispersion of the composite in terpineol with ethylcellulose as described in previous papers [14]. In order to improve the mechanical and thermal stability of the membrane and the thermal expansion compatibility, a porous interlayer was deposited 
using 1.5 $\mu \mathrm{m}$ PMMA particles as pore former. The inks were refined using a three-roller mill and its rheological behavior was also studied.

The density and porosity of the substrates was determined by Archimedes method according to the ASTM C373-88 [32], using the following equation (eq. 3)

$$
P=\frac{M-D}{M-S} \cdot \rho_{H_{2} O} \cdot 100
$$

where $P$ is the open porosity, $M$ is the mass of the water-saturated sample, $D$ the mass of the dry sample, $S$ is the mass of the sample immersed in water and $\rho_{\text {H2O }}$ is the density of the water at the experiment temperature. The microstructure of the sintered samples was registered using a XL-30 scanning electron microscope (Philips, Netherlands).

The in-plane electrical conductivity of the films was measured by standard four-point DC technique on films deposited on 3YSZ substrates by using silver wires and paste for contacting. Measurements were recorded as the temperature decreases from 800 to $400{ }^{\circ} \mathrm{C}$ at $1{ }^{\circ} \mathrm{C} / \mathrm{min}$ at a constant atmosphere, in different oxygen partial pressures $\left(\mathrm{pO}_{2}\right)$. The constant current was supplied by a programmable current source (Keithley 2601), and the voltage drop through the sample was detected by a multimeter (Keithley 3706).

Oxygen permeation studies were carried out in a lab-scale quartz reactor. Synthetic air (21 vol. $\% \mathrm{O}_{2}$ in the feed stream) or pure oxygen was fed in to the oxygen-rich chamber, while argon was used as the sweep gas on the permeate side. Both gases were fed at atmospheric pressure. Inlet gases were preheated in order to ensure the correct gas temperature for contact with the membrane surface. This is particularly important when high gas flow rates are employed. All streams were individually mass flow controlled. The temperature was measured by a thermocouple attached to the membrane. A PID controller maintained temperature variations within $2^{\circ} \mathrm{C}$ of the set point. 


\section{Results}

\subsection{Porous substrates}

For the wet processing techniques as slip casting, the main requirement is to obtain a stable suspension and, for this purpose, the use of different additives as organic molecules is a common practice [29]. These additives modify the colloidal behavior of the solid particles in the suspension, improving their stability and allowing increasing the solid content of the slurries. Figure 3 plots the zeta potential of the $3 Y S Z$ as a function of $\mathrm{pH}$ suspension with and without an anionic dispersant. As shown in Figure 3, 3YSZ presents an isoelectric point of 5.5 and a maximum superficial charge of $-16 \mathrm{mV}$ at $\mathrm{pH} 10$. The addition of $0.4 \mathrm{wt}$. \% of Dolaplix CE64 (Zchimmer \& Schwartz, Germany) causes that the isoelectric point of the 3YSZ shifts to 4.3 and the maximum repulsion value increases to $-26 \mathrm{mV}$ at $\mathrm{pH} 10$, allowing obtaining more stable 3YSZ suspensions.

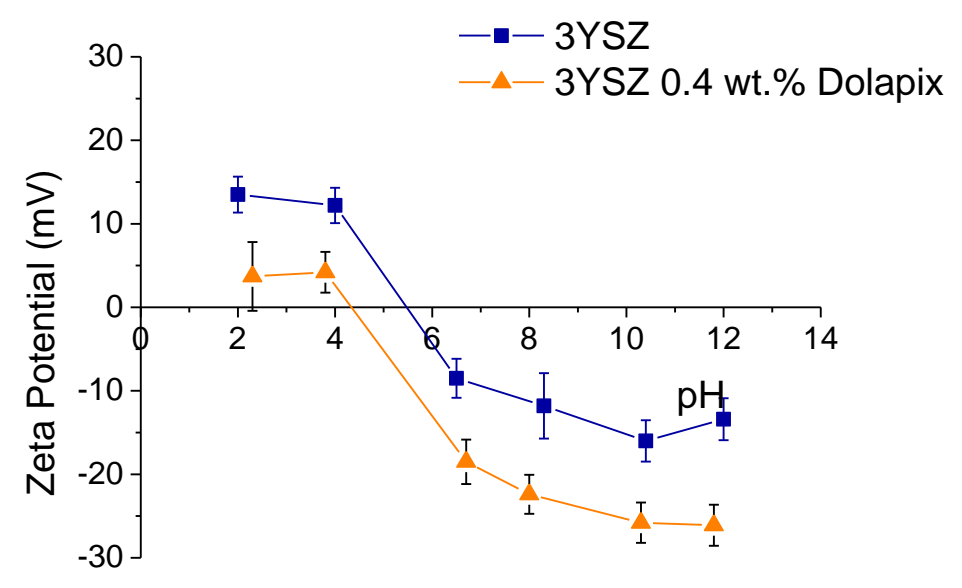

Figure 3 Zeta potential vs. pH of the 3YSZ powder and 3YSZ powder with 0.4 wt. \% of Dolapix CE64.

According to the zeta potential study, the casting slurries were prepared at $\mathrm{pH} 10$ in water with a 0.4 wt. \% of Dolaplix. Aiming to produce porous 3YSZ substrates, pore former particles were added to the 3YSZ slurry in two different amounts, 40 vol. $\%$ and 60 vol. \%. The solid content was set at $35 \mathrm{vol}$. \% for all the suspensions. The effect of the addition of the pore former contents in the rheology was also studied. Figure 4 presents the flow curves of the 3YSZ slurries without pore former, with 40 vol. \% of S-050 and with 60 vol. \% in a logarithmic plot. 


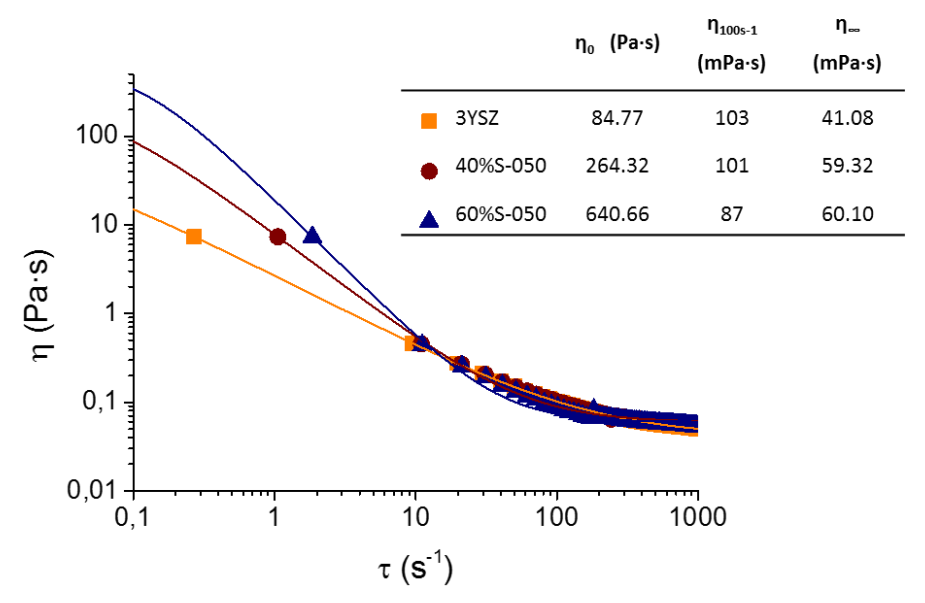

Figure 4 Logarithmic plot of the viscosity versus shear rate for the $3 Y S Z$ slurries with different amount of S-050 and them rheological parameters

All the slurries present a pseudo plastic behavior with viscosities at shear rates of $100 \mathrm{~s}^{-1}$ close to $100 \mathrm{mPa} \cdot \mathrm{s}$ and therefore are suitable for slip casting. The slurries were casted in a plaster mold using a plastic cylinder, dried at room temperature and sintered at $1450^{\circ} \mathrm{C}$ for $2 \mathrm{~h}$. The sintered samples were characterized based on their microstructure and density. Figure 5 shows the SEM micrographs of polished cross-sections for the substrates casted using 3YSZ slurries with 40 vol. \% of S-005 (Figure 5a), S-020 (Figure 5b) and S-050 (Figure 5c). In order to improve the porosity and it interconnectivity, the pore former addition was increased to 60 vol. \%, and also an irregularly-shaped PMMA particles (F-150) were studied. In Figure 6, the microstructures of the polished cross-sections for the samples processed with $60 \mathrm{vol}$. \% of S020 (Figure 6a), S-050 (Figure 6b) and F-150 (Figure 6c) can be observed.
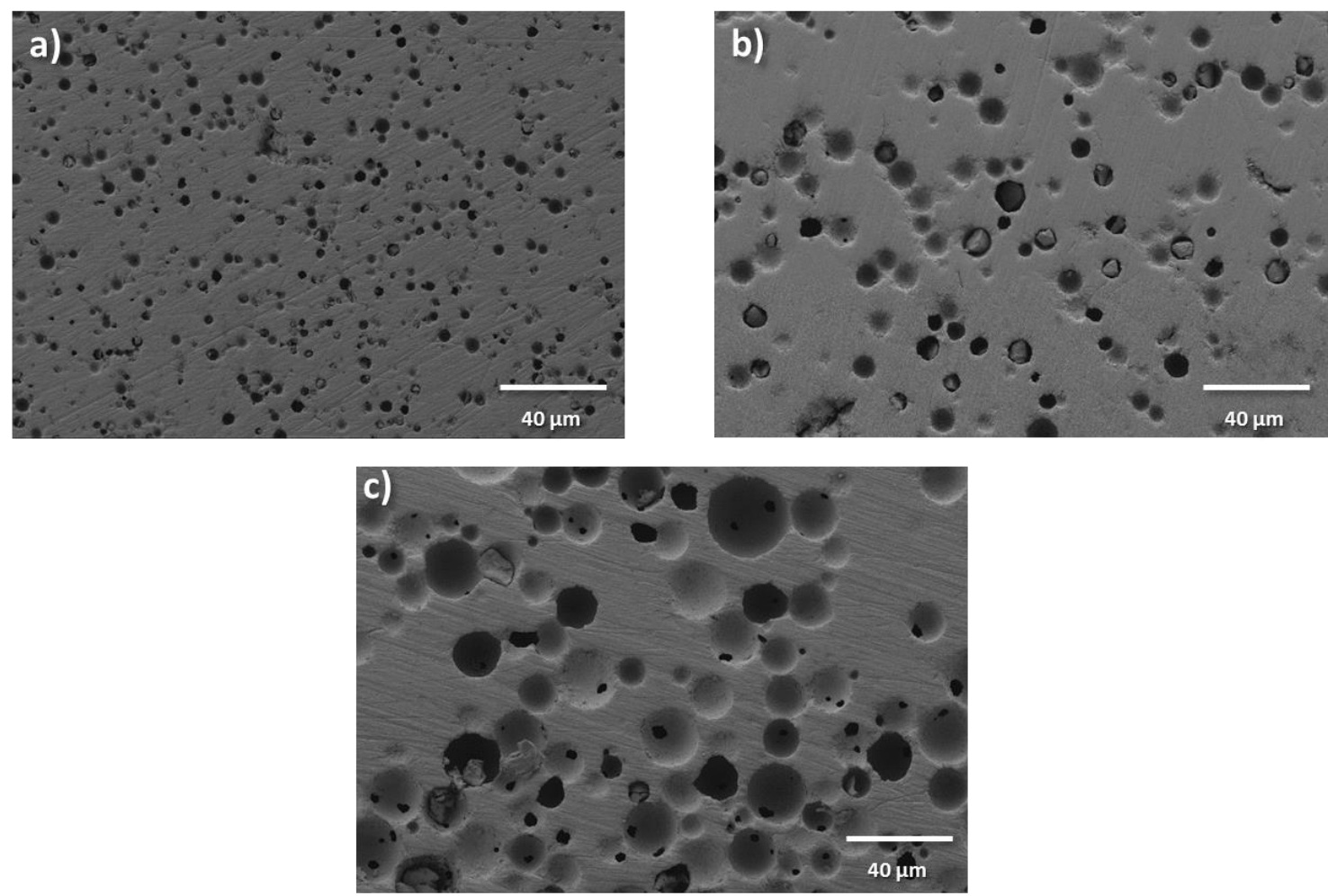

Figure 5 Microstructure of the $3 Y$ SZ samples from the suspensions with 40 vol\% of a) S-005, b) S-020 and c) S-050. 

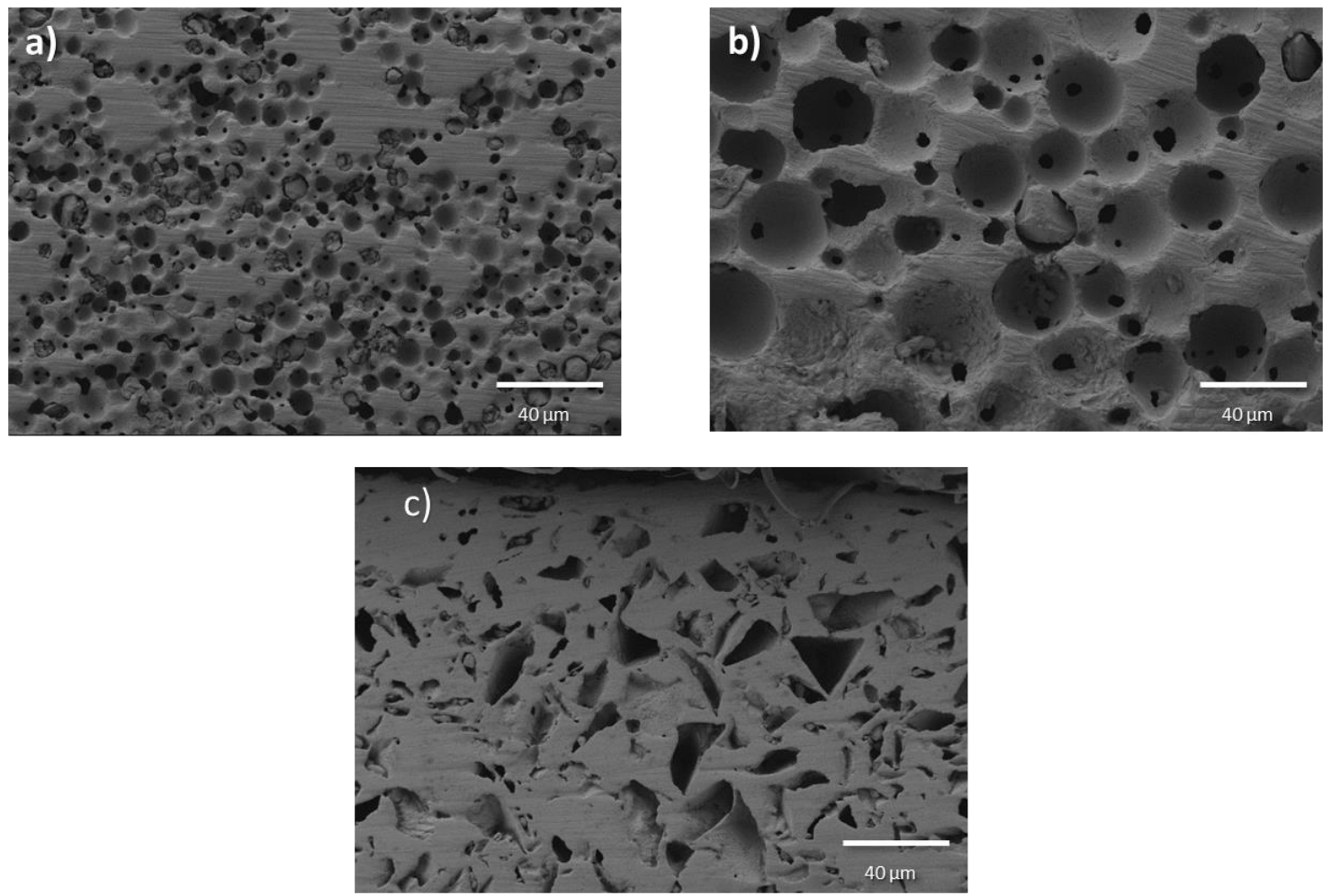

Figure 6 Microstructure of the 3YSZ samples from the suspensions with $60 \mathrm{vol}$. \% of a) S-020, b) S-050 and c) F-150.

It should be noted that for both sets of samples, the formed pores present a shape and size related to the original pore former as could be expected. As a consequence, the use of spherical pore-former particles produces more closed porosity even for the samples with 60 vol. \% of pore former. Due to the requirement of interconnectivity between pores to allow the gas diffusion during membrane operation, an improvement in the microstructure was done by mixing spherical-like pore former S-050 with F-150 flake shaped particles (Figure 7).
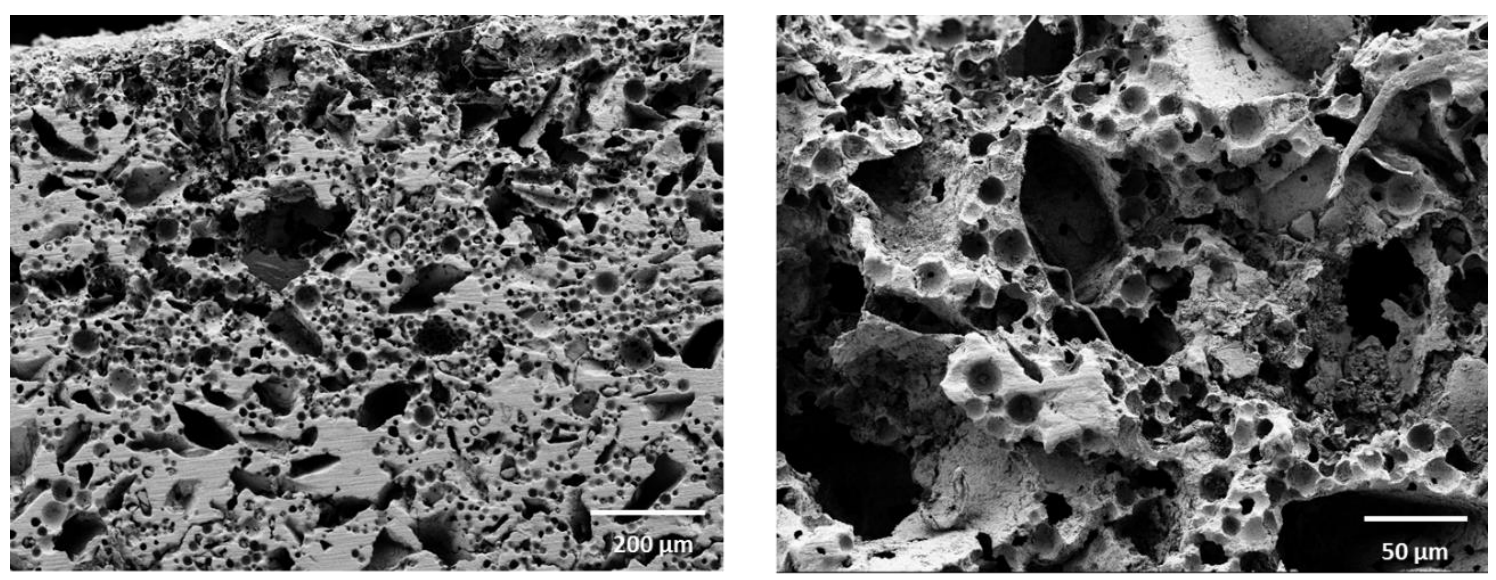

Figure 7 Micrographs of the F-150+S-050 sample

In addition to the microstructure study, the density of the sintered substrates was determined by Archimedes method. Table 2 summarizes the values of the relative porosity of all the substrates prepared and are compared with the pore former fraction added in the slurries. 
Table 2 Porosity of the prepared substrates at 1450 o C comparing to the volume of pore former added in the slurry

\begin{tabular}{lcc}
\hline Pore Former & PMMA vol\% & Rel. Porosity (at 1450年) \\
\hline S-006 & 40 & $23 \%$ \\
S-020 & 40 & $25 \%$ \\
S-050 & 40 & $25 \%$ \\
S-006 & 60 & $40 \%$ \\
S-020 & 60 & $44 \%$ \\
S-050 & 60 & $47 \%$ \\
F-150 & 60 & $48 \%$ \\
F-150+S-050 & 60 & $50 \%$ \\
\hline
\end{tabular}

In order to characterize the permeation properties of the substrates, the flow resistance of the samples was measured in terms of pressure drop $(\Delta p)$ as a function of the imposed air flow rate at ambient pressure and room temperature (Figure 8). As SEM and porosity analyses revealed, the samples prepared from suspensions with $40 \mathrm{vol}$. \% of pore former do not present enough open porosity at all and gas flow was negligible for these samples. Therefore, the pressure drop could be measured only for the samples prepared from suspensions containing a 60 vol. \% of pore former.

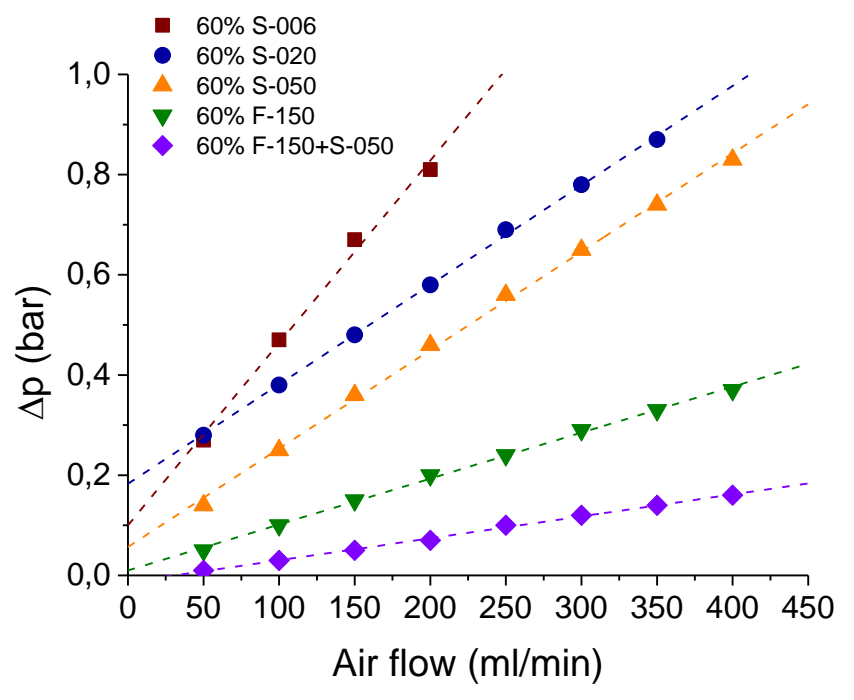

Figure 8 Pressure drop measurement as a function of the air inlet flow rate through the substrates.

As expected for the porous bodies, all the samples present increasing pressure drop with higher air flow rates. Comparing the values in the Figure 8 it can be ascertained that the increment in PMMA particle size causes a decrease in the pressure drop, being a major difference when F-150 particles are used. For the S-050 sample, the pressure decreases 0.48 bar at $200 \mathrm{ml} / \mathrm{min}$, while for the F-150 sample the pressure drops to 0.19 bar at the same air flow rate. As previously observed at the micrographs in Figure 7, the combination of F-150 and 
S-050 particles improve the pore connectivity, which is reflected in the decreased pressure drop, i.e. down to 0.07 bar at $200 \mathrm{ml} / \mathrm{min}$.

\subsection{MIEC layer}

The MIEC layer and the porous interlayer were deposited by screen-printing. The ink was prepared by dispersing the solid powders in a dissolution of $6 \mathrm{wt}$. \% ethylcellulose in terpineol. The rheological behavior of both inks is presented in Figure 9 .

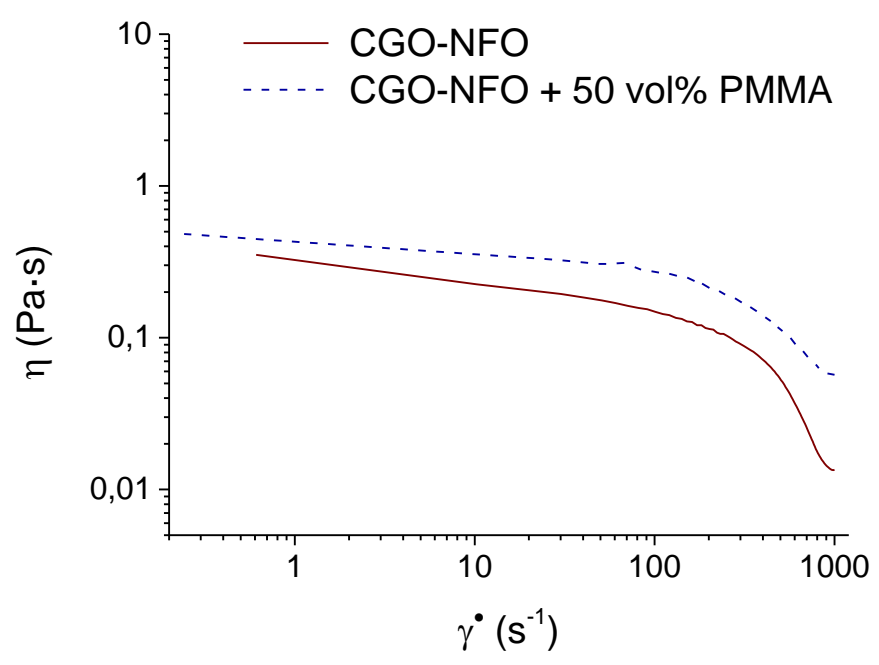

Figure 9 Logarithmic plot of the rheological behavior of the composite pastes

Both inks present a pseudoplastic behavior, i.e., viscosity decreases slightly with the shear rate until $400 \mathrm{~s}^{-1}$ and then it drops. This kind of behavior is appropriate for screen-printing technique because when the ink is squeezed, its viscosity is very low and can be deposited on the substrate and when the shearing is stopped, viscosity increases fast avoiding the spread on the surface.

In order to co-sinter both CGO-NFO layers and the 3YSZ substrate, the substrate was pretreated at $1150^{\circ} \mathrm{C}$ for $1 \mathrm{~h}$, then top-layers were screen-printed and the complete assembly sintered at $1450^{\circ} \mathrm{C}$ for $2 \mathrm{~h}$. The microstructure of the deposited films was analyzed by SEM (Figure 10). Figure 10a shows the superficial microstructure at the edge of the deposited layers, where three areas can be observed: the substrate, the porous interlayer (CGO-NFOPMMA) and the dense MIEC layer (CGO-NFO). The surface of the dense layer is shown in Figure $10 \mathrm{~b}$ and the cross-section of the substrate and both layers in Figure 10c. 

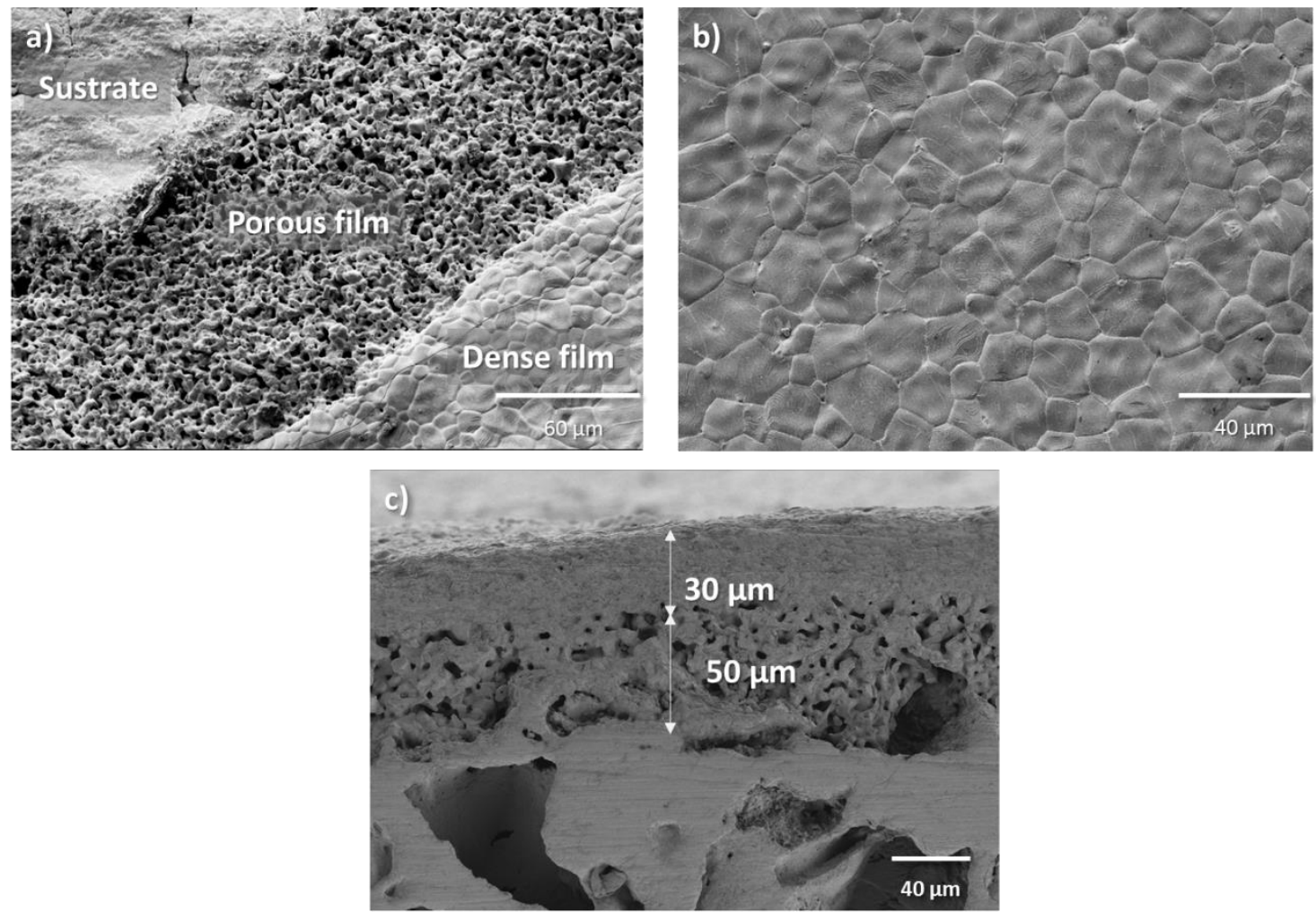

Figure 10 SEM images of the membranes: (a-b) top views and (c) polished cross-section

In order to characterize the membrane, the in-plane total conductivity of the top MIEC coatings was studied by 4-point DC measurements from 800 to $400{ }^{\circ} \mathrm{C}$ under different atmospheres (Figure 11a). Figure 11b shows the conductivity of the membrane as a function of the $\mathrm{pO}_{2}$ at three different temperatures. 
a)

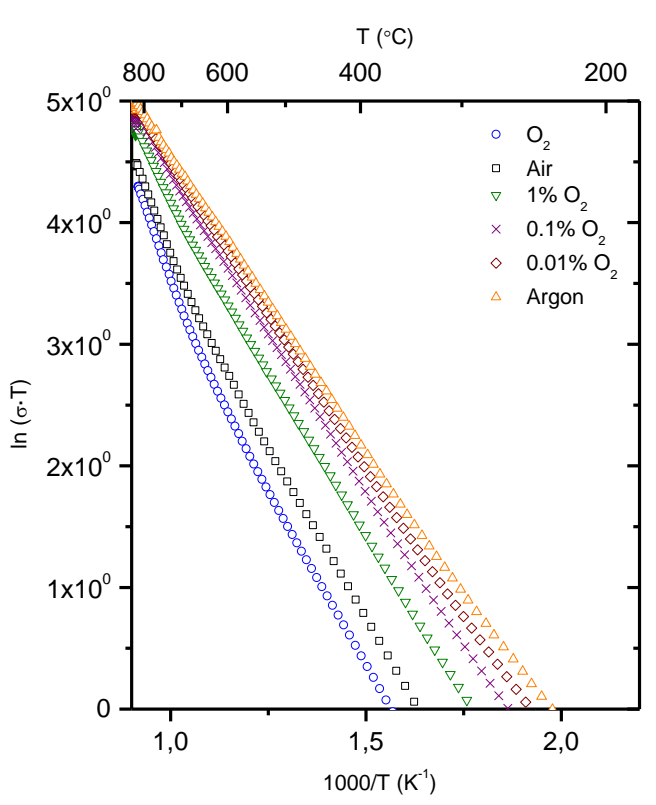

b)

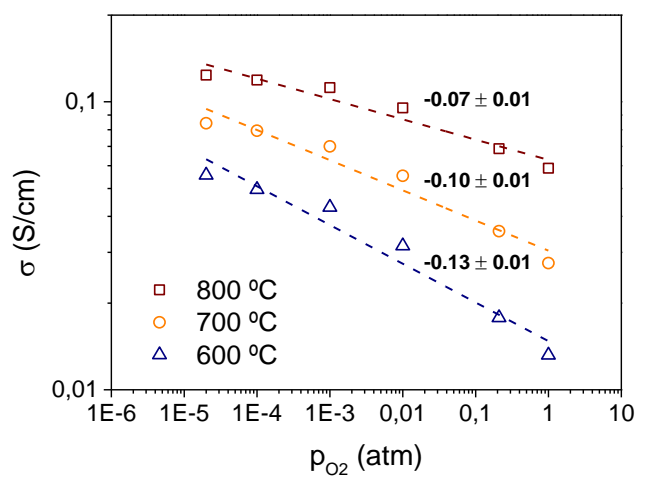

Figure 11 In-plane conductivity of a 30 $\mu$ m-thick CGO-NFO membrane at a) different atmospheres and b) at different temperatures as a function of $\mathrm{O}_{2}$ partial pressure

\section{Discussion}

The zeta potential study allows preparing stable 3YSZ suspensions in water with 35 vol. \% of solids for slip-casting. The rheological study presented in Figure 4 compares the flow curves for 3YSZ suspensions with different amounts of pore former and their rheological parameters according to the Cross model (eq. 2). The incorporation of the S-050 particles to the slurries implies (1) the increase of the $\eta_{0}$ value and thus the sedimentation stability; and (2) the decrease in the viscosity at slip-casting shear rate $\left(100 \mathrm{~s}^{-1}\right)$ and the $\eta_{\infty}$, which involves a less effective homogenization of the suspensions. Taking this into account, the addition of pore former enables to improve the slip-casting characteristics of the slurries.

The samples with 40 vol. \% of pore former in the slurry composition are presented at the micrographs in Figure 5. The pores in these samples are spherical and the actual size and shape is directly related to the pore former particles added to the slurries. This porous system presents very low connectivity giving rise to a close porosity, which makes difficult the flow of the feed gas through the membranes. The Archimedes measurements for these samples (summarized in Table 2 ) revealed that a decrease in porosity of about $15 \%$ takes place during 
the sintering process. The increment of the pore former volume fraction up to $60 \mathrm{vol}$. $\%$ in the slurry has a direct influence on the microstructure as shown in Figure 6. However, as for the case of the previous samples, the porosity obtained from spherical PMMA particles (Figure 6a and Figure 6b) presents low interconnectivity. On the other hand, the use of the flake-like PMMA particles seems to increase the contact between pores (Figure 6c) but is insufficient. The porosity values (Table 2 ) show a decrement of $12 \%-20 \%$ for the samples with spherical pore former particles, similar to the previous samples. The lowest loss in porosity is observed for the sample prepared with F-150 particles and the highest loss for the sample with the smallest pore former (S-006).

In order to improve the connectivity between pores, it was decided to use a combination of spherical (S-050) and flake-like particles in a 1:1 ratio, in a 60 vol. \% (Figure 7). The resulting samples pieces present $50 \%$ of porosity with high interconnectivity, which improves the gas permeation through the substrate towards the MIEC layers. Therefore, this formulation was selected to prepare the substrates for the asymmetric membranes.

Suitability of the substrates was studied in terms of their resistance against an air flow, measuring their pressure drop. The obtained data, plotted at Figure 8, confirm that the use of a combination of F-150 and S- 050 particles, in a total volume of $60 \%$ in the slurry composition, improves the permeation of the substrates.

As described before, the substrates where pre-treated at 1150 ㅇ $\mathrm{C}$ in air prior to CGO-NFO deposition, and later the complete assembly was sintered the membrane at $1450 \circ \mathrm{C}$. This procedure allows resembling the thermal expansion of the layers and substrate, and improving the final density of the dense layer due to the contraction of the substrate. Figure 10a shows a superficial view of both CGO-NFO layers and the substrate at the edge of the deposition, where the different in density and morphology between both screen-printed layers after sintering can be observed. The top layer of CGO-NFO presents a good sintering and high density as shown in the top view of the membrane (Figure 10b). These results are confirmed in the cross-section view of the membrane in Figure 10c, where the dense top layer $30 \mu \mathrm{m}$ of thickness, and the interlayer $50 \mu \mathrm{m}$ of thickness. It should be noted that the porosity of the interlayer is open with connectivity while the top-layer is gas tight.

The in-plane electrochemical measurements (Figure 11) show conductivity values above 50 $\mathrm{mS} \cdot \mathrm{cm}^{-2}$ and this conductivity level can only be related to electronic conduction. This evidences the presence of a percolating network of the NFO phase - electronic conducting phase of the composite. The conductivity values are in the same order of magnitude than that observed for NFO bulk (e.g. $250 \mathrm{mS} \cdot \mathrm{cm}^{-2}$ at $800{ }^{\circ} \mathrm{C}$ in air) and thin-film samples [7] and this suggests that the electronic pathways are as abundant as ionic pathways. In principle, the conduction properties are acceptable for application as oxygen transport membrane. In general, the conductivity (Figure 11a) presents a simple Arrhenius behavior although the activation energy becomes slightly lower at temperatures below $600{ }^{\circ} \mathrm{C}$ and this effect is more visible at high $\mathrm{pO}_{2}$. Figure $11 \mathrm{~b}$ reveals that the conductivity decreases with $\mathrm{pO}_{2}$. This is another sign of the important contribution of electronic transport in the total transport in these deposited films. At $600{ }^{\circ} \mathrm{C}$, the $p \mathrm{O}_{2}$ dependence $\left(p^{\prime \prime} \mathrm{O}_{2}\right)$ follows a power law with exponent $n$ close to $-1 / 6$, which is characteristic for $n$-type conductors. This result is in line with the $n$-type electronic character reported for monolith Tb-doped $\mathrm{CeO}_{2}-\mathrm{NFO}$ composite membranes with different NFO contents $[9,33]$. The exponent value, $n$, becomes lower with increasing temperatures and this may be 
ascribed to the higher contribution of ionic conduction and the reduction of electronic charge carrier concentration in the material (electrons) with increasing temperatures.

As a final test of the function of the membrane, the selective oxygen permeation was studied in the temperature range of $850-750 \stackrel{\circ}{\circ}$ under an Air/Argon gradient $\left(300 \mathrm{ml} \cdot \mathrm{min}^{-1}\right.$ for both streams). Figure 12 depicts the oxygen flux $\mathrm{J}\left(\mathrm{O}_{2}\right)$ dependence with temperature for the membrane with support prepared with F-150 and S-050 pore formers. An oxygen flux of ca.

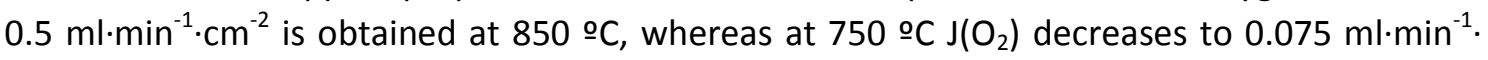
$\mathrm{cm}^{-2}$. Moreover, the oxygen permeation results of a $0.8 \mathrm{~mm}$-thick membrane are presented with the aim of studying the effect of thickness reduction. Despite the membranes were tested in different temperature ranges, a fair comparison can be performed by interpolating available $\mathrm{J}\left(\mathrm{O}_{2}\right)$ values at higher temperatures, taking into account that these membranes typically present a change in the Ea above $800{ }^{\circ} \mathrm{C}$ [33-35]. Therefore, a significant improvement in oxygen permeation can be observed for the thinner membrane, with a 1.000 -fold improvement at $850 \stackrel{\circ}{\circ} \mathrm{C}$ and an expected 40-times gain in $\mathrm{J}\left(\mathrm{O}_{2}\right)$ at $950 \stackrel{\circ}{\circ}$. Due to the interpolation, this improvement may be handled as an approximation. Nevertheless, the improvement in the permeation flux thanks to thickness reduction achieved in the supported membrane is very visible.

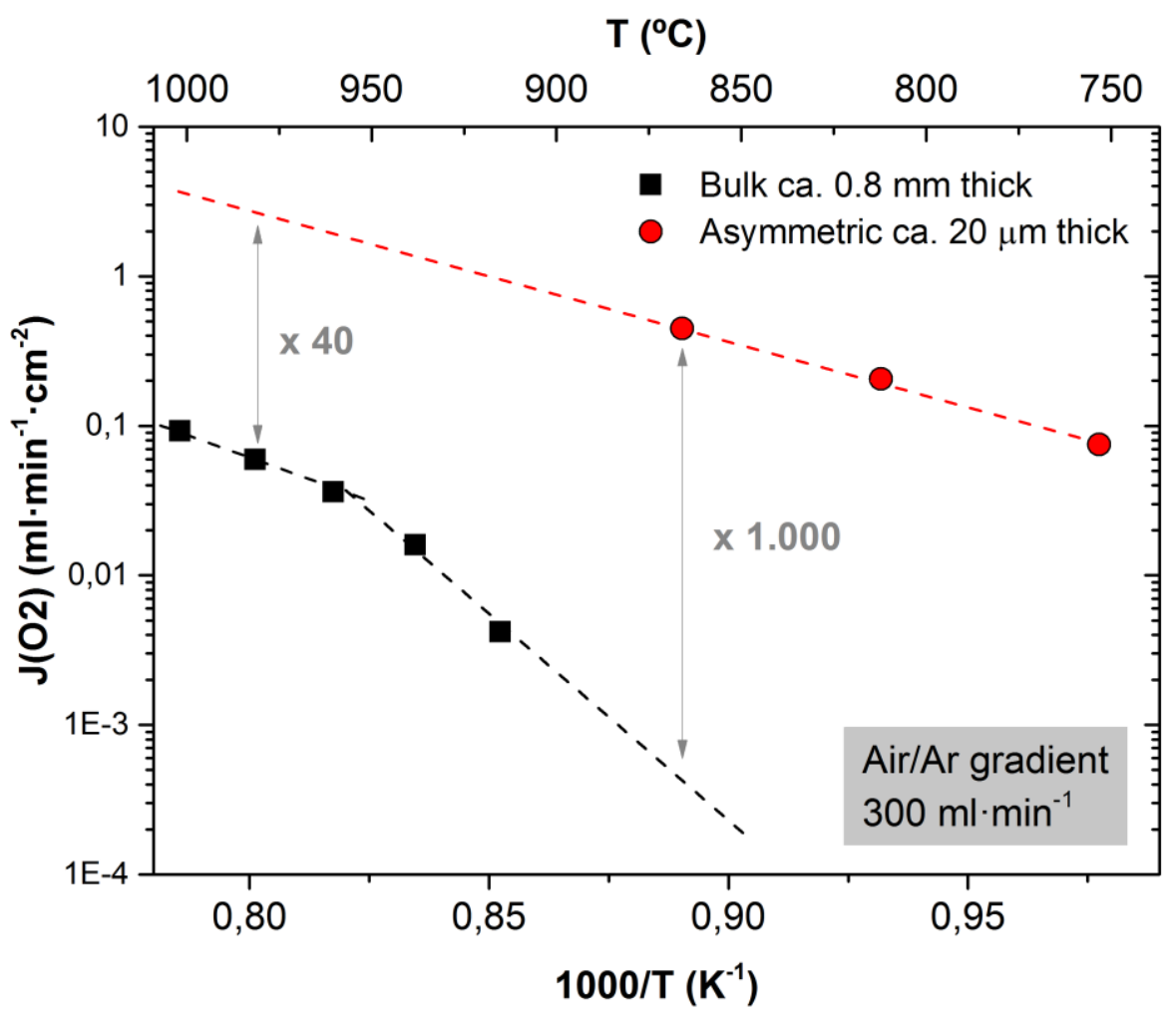

Figure 12 Comparison of the oxygen fluxes as a function of the temperature between a bulk membrane of CGO-NFO and the asymmetric membrane presented in this paper 


\section{Conclusions}

The main conclusions and achievements of the present study on the manufacture by slipcasting and characterization of $3 \mathrm{YSZ}$ supports for $\mathrm{O}_{2}$-separation membranes are:

- Stable aqueous suspensions of YSZ and PMMA particles were formulated. PMMA is employed as pore former and different particle sizes and morphologies were considered.

- The effect of the PMMA volume in the slip as well as its particle size and morphology were studied. Namely, the effect on the porosity magnitude and nature, and the permeation resistance was characterized. In this sense, the combination of spherical and flake-like PMMA particles in a 60 vol. \% in the slip make it possible to produce open porosity in the YSZ substrates suitable for fast gas diffusion.

- Complete $\mathrm{O}_{2}$-separation membranes were prepared by depositing by screen-printing two top layers made of CGO-NFO, a mixed ionic-electronic composite material: (1) a porous interlayer -acting as gas diffusion layer and catalytic layer; and (2) a dense and 20-30 $\mu \mathrm{m}$ gastight film, for the selective oxygen separation.

- $\quad$ CGO-NFO asymmetric membranes with 3YSZ substrate obtained by slip casting showed promising $\mathrm{O}_{2}$ production features, with better results than a monolithic CGO-NFO membrane in preliminary studies.

- Slip casting processing route opens the door to obtain MIEC membranes with complex shapes that can meet the necessary requirements depending on their application either as $\mathrm{O}_{2}$ separators or catalytic membrane reactors for oxidative conversions.

\section{Acknowledgements}

Financial funding from the Spanish Government (ENE2014-57651 and SEV-2012-0267 grants) is gratefully acknowledged.

\section{References}

[1] S.S. Hashim, A.R. Mohamed, S. Bhatia, Oxygen separation from air using ceramic-based membrane technology for sustainable fuel production and power generation, Renew. Sustain. Energy Rev. 15 (2011) 1284-1293. doi:10.1016/j.rser.2010.10.002.

[2] T. Takahashi, T. Esaka, H. Iwahara, Electrical conduction in the sintered oxides of the system Bi2O3BaO, J. Solid State Chem. 16 (1976) 317-323. doi:10.1016/00224596(76)90047-5.

[3] B. Cales, J.F. Baumard, Oxygen semipermeability and electronic conductivity in calciastabilized zirconia, J. Mater. Sci. 17 (1982) 3243-3248. doi:10.1007/BF01203490.

[4] J. Sunarso, S. Baumann, J.M. Serra, W.A. Meulenberg, S. Liu, Y.S. Lin, et al., Mixed ionicelectronic conducting (MIEC) ceramic-based membranes for oxygen separation, J. Memb. Sci. 320 (2008) 13-41. doi:10.1016/j.memsci.2008.03.074.

[5] J.H. Joo, K.S. Yun, J.H. Kim, Y. Lee, C.Y. Yoo, J.H. Yu, Substantial Oxygen Flux in DualPhase Membrane of Ceria and Pure Electronic Conductor by Tailoring the Surface, ACS 
Appl. Mater. Interfaces. 7 (2015) 14699-14707. doi:10.1021/acsami.5b03392.

[6] W. Fang, F. Liang, Z. Cao, F. Steinbach, A. Feldhoff, A mixed ionic and electronic conducting dual-phase membrane with high oxygen permeability, Angew. Chemie - Int. Ed. 54 (2015) 4847-4850. doi:10.1002/anie.201411963.

[7] C. Solis, S. Somacescu, E. Palafox, J.M. Serra, Particular Transport Properties of NiFe2O4 Thin Films at High Temperatures, (2014) 2-4.

[8] C. Gaudillère, L. Olivier, P. Vernoux, C. Zhang, Z. Shao, D. Farrusseng, Alternative perovskite materials as a cathode component for intermediate temperature singlechamber solid oxide fuel cell, J. Power Sources. 195 (2010) 4758-4764. doi:10.1016/j.jpowsour.2010.02.058.

[9] M.P. Lobera, J.M. Serra, S.P. Foghmoes, M. Søgaard, A. Kaiser, On the use of supported ceria membranes for oxyfuel process/syngas production, J. Memb. Sci. 385-386 (2011) 154-161. doi:10.1016/j.memsci.2011.09.031.

[10] V. V. Zyryanov, V.A. Sadykov, G.M. Alikina, Design of Multilayer Ceramic MIEC Membranes, Sep. Sci. Technol. 42 (2007) 2849-2861.

doi:10.1080/01496390701558300.

[11] P. Pandey, R.S. Chauhan, Membranes for gas separation, Prog. Polym. Sci. 26 (2001) 853-893. doi:10.1016/S0079-6700(01)00009-0.

[12] S. Baumann, W.A. Meulenberg, H.P. Buchkremer, Manufacturing strategies for asymmetric ceramic membranes for efficient separation of oxygen from air, J. Eur. Ceram. Soc. 33 (2013) 1251-1261. doi:10.1016/j.jeurceramsoc.2012.12.005.

[13] Y. Gu, G. Meng, A model for ceramic membrane formation by dip-coating, J. Eur. Ceram. Soc. 19 (1999) 1961-1966. doi:10.1016/S0955-2219(99)00013-8.

[14] J.M. Serra, J. Garcia-Fayos, S. Baumann, F. Schulze-Küppers, W.A. Meulenberg, Oxygen permeation through tape-cast asymmetric all-La0.6Sr0.4Co0.2Fe0.803- $\delta$ membranes, J. Memb. Sci. 447 (2013) 297-305. doi:10.1016/j.memsci.2013.07.030.

[15] P. Pinacci, E. Louradour, L. Wimbert, M. Gindrat, M.O. Jarligo, R. Vassen, et al., Dense membranes for oxygen and hydrogen separation (DEMOYS): project overview and first results, Energy Procedia. 37 (2013) 1030-1038. doi:10.1016/j.egypro.2013.05.199.

[16] P. Lemes-rachadel, G. Sachinelli, R. Antonio, F. Machado, Current Developments of Mixed Conducting Membranes on Porous Substrates, 17 (2014) 242-249.

[17] S. Pirou, J. Gurauskis, V. Gil, M. Sogaard, P.V. Hendriksen, A. Kaiser, et al., Oxygen permeation flux through 10Sc1YSZ-MnCo2O4 asymmetric membranes prepared by two-step sintering, Fuel Process. Technol. 152 (2016) 192-199. doi:10.1016/j.fuproc.2016.06.019.

[18] E. Mercadelli, D. Montaleone, A. Gondolini, P. Pinasco, A. Sanson, Tape-cast asymmetric membranes for hydrogen separation, Ceram. Int. (2017). doi:10.1016/j.ceramint.2017.03.099.

[19] C. Gaudillere, J.M. Serra, Freeze-casting: Fabrication of highlyporous and hierarchical ceramic supports for energy applications, Bol. La Soc. Esp. Ceram. Y Vidr. 55 (2016) 4554. doi:10.1016/j.bsecv.2016.02.002.

[20] J. Seuba, J. Leloup, S. Richaud, S. Deville, C. Guizard, A.J. Stevenson, Fabrication of icetemplated tubes by rotational freezing: microstructure, strength, and permeability, J. 
Eur. Ceram. Soc. 37 (2016) 2423-2429. doi:10.1016/j.jeurceramsoc.2017.01.014.

[21] A. V. Kovalevsky, V. V. Kharton, F.M.M. Snijkers, J.F.C. Cooymans, J.J. Luyten, J.R. Frade, Processing and oxygen permeability of asymmetric ferrite-based ceramic membranes, Solid State lonics. 179 (2008) 61-65. doi:10.1016/j.ssi.2007.12.027.

[22] A.V. Kovalevsky, A.A. Yaremchenko, V.A. Kolotygin, F.M.M. Snijkers, V.V. Kharton, A. Buekenhoudt, et al., Oxygen permeability and stability of asymmetric multilayer Ba0.5Sr0.5Co0.8Fe0.2O3- $\delta$ ceramic membranes, Solid State Ionics. 192 (2011) 677681. doi:10.1016/j.ssi.2010.05.030.

[23] S. Ovtar, J. Gurauskis, A. Bj??rnetun Haugen, C. Chatzichristodoulou, A. Kaiser, P.V. Hendriksen, Oxygen transport properties of tubular Ce0.9Gd0.101.95-

La0.6Sr0.4FeO3???d composite asymmetric oxygen permeation membranes supported on magnesium oxide, J. Memb. Sci. 523 (2017) 576-587.

doi:10.1016/j.memsci.2016.09.060.

[24] Z. Liu, G. Zhang, X. Dong, W. Jiang, W. Jin, N. Xu, Fabrication of asymmetric tubular mixed-conducting dense membranes by a combined spin-spraying and co-sintering process, J. Memb. Sci. 415-416 (2012) 313-319. doi:10.1016/j.memsci.2012.05.011.

[25] M.B. Choi, D.K. Lim, S.Y. Jeon, H.S. Kim, S.J. Song, Oxygen permeation properties of BSCF5582 tubular membrane fabricated by the slip casting method, Ceram. Int. 38 (2012) 1867-1872. doi:10.1016/j.ceramint.2011.10.012.

[26] J.A. Queiroga, E.H.M. Nunes, D.F. Souza, D.C.L. Vasconcelos, V.S.T. Ciminelli, W.L. Vasconcelos, Microstructural investigation and performance evaluation of slip-cast alumina supports, (2016). doi:10.1016/j.ceramint.2016.12.037.

[27] C. Ceramics, Porous Ceramic Processing, (n.d.) 1-4.

[28] P. Monash, G. Pugazhenthi, P. Saravanan, Various fabrication methods of porous ceramic supports for membrane applications, Rev. Chem. Eng. 29 (2013) 357-383. doi:10.1515/revce-2013-0006.

[29] J.A. Lewis, Colloidal Processing of Ceramics, 59 (2000) 2341-2359.

[30] A.R. Studart, E. Amstad, L.J. Gauckler, Colloidal stabilization of nanoparticles in concentrated suspensions., Langmuir. 23 (2007) 1081-90. doi:10.1021/la062042s.

[31] L.J. Gauckler, T. Graule, F. Baader, Ceramic forming using enzyme catalyzed reactions, Mater. Chem. Phys. 61 (1999) 78-102. doi:10.1016/S0254-0584(99)00117-0.

[32] W. Loop, Water Absorption, Bulk Density, Apparent Porosity, and Apparent Speci c Gravity of Fired Whiteware Products 1, 88 (2009) 13-14. doi:10.1520/C037388R06.edges.

[33] J. Garcia-Fayos, M. Balaguer, J.M. Serra, Dual-Phase Oxygen Transport Membranes for Stable Operation in Environments Containing Carbon Dioxide and Sulfur Dioxide, ChemSusChem. 8 (2015) 4242-4249. doi:10.1002/cssc.201500951.

[34] M. Balaguer, J. García-Fayos, C. Solís, J.M. Serra, Fast Oxygen Separation Through SO2 and CO2 -Stable Dual-Phase Membrane Based on NiFe $204-\mathrm{Ce} 0.8 \mathrm{~Tb} 0.20$ 2- $\delta$, Chem. Mater. 25 (2013) 4986-4993. doi:10.1021/cm4034963.

[35] C. Gaudillere, J. Garcia-Fayos, J.M. Serra, Enhancing oxygen permeation through hierarchically-structured perovskite membranes elaborated by freeze-casting, J. Mater. Chem. A. 2 (2014) 3828. doi:10.1039/c3ta14069e. 